Article

\title{
Thermal Oxidation of Polyolefins by Mild Pro-Oxidant Additives Based on Iron Carboxylates and Lipophilic Amines: Degradability in the Absence of Light and Effect on the Adhesion to Paperboard
}

\author{
Tuan-Anh Nguyen ${ }^{1, *}, \emptyset y$ vind Weiby Gregersen ${ }^{1}$ and Ferdinand Männle ${ }^{2, *}$ \\ ${ }^{1}$ Department of Chemical Engineering, Norwegian University of Science and Technology, \\ N-7491 Trondheim, Norway; E-Mail: oyvind.gregersen@chemeng.ntnu.no \\ ${ }^{2}$ Synthesis and Properties, SINTEF Materials and Chemistry, N-0314 Oslo, Norway \\ * Authors to whom correspondence should be addressed; \\ E-Mails: ferdinand.maennle @ sintef.no (F.M.); tuananh210281 @gmail.com (T.-A.N.); \\ Tel.: +47-98-28-2491 (F.M.); +47-40-30-8660 (T.-A.N.).
}

Academic Editor: Philipp Vana

Received: 14 June 2015 / Accepted: 5 August 2015 / Published: 17 August 2015

\begin{abstract}
Marine and inland pollution by non-degradable plastic bags and other plastic articles is a topic of great concern. Natural degradation processes based on oxidation of plastic pollutants could possibly contribute to limit the extent of pollution. Thermal degradation of polyolefins in the absence of light by non-polluting pro-oxidants has not been presented before. In this study, we show that two amines, stearyl amine and [(3-(11-aminoundecanoyl) amino) propane-1-] silsesquioxane (amino-POSS) in combination with ferric stearate $\left(\mathrm{FeSt}_{3}\right)$ tremendously accelerate the thermal oxidation of polyolefins compared with reference samples. Both amines and $\mathrm{FeSt}_{3}$ are to a large extent based on renewable resources. Polyethylene and polypropylene samples containing less than $100 \mathrm{ppm}$ of iron and $1 \%$ of amine were extremely brittle after 10 days in a circulation oven in the absence of light. No significant degradation could be seen with samples containing iron but no amine. In a different application, the initial oxidation of polyethylene can be used in order to increase its adhesion to cardboard. Excellent adhesion between polyethylene and cardboard is important for liquid packaging based on renewable resources. Amino-POSS has been chosen for food packaging applications due to its expected lower leakage from polyethylene (PE) compared with stearyl amine. Film samples of PE/amino-POSS/FeSt 3 blends were partly oxidized in a circulation oven. The oxidation was documented by
\end{abstract}


increased carbonyl index (CI) and melt flow index (MFI). The limited extent of oxidation has been proved by unchanged tensile strength and only moderate changes in elongation at break when compared to reference polyethylene films containing no $\mathrm{FeSt}_{3}$ or amino-POSS. The PE/amino-POSS/FeSt 3 blends were compression moulded to paperboard. The adhesion of non-aged blends to paperboard decreased with increasing amino-POSS content which is in good compliance with an earlier reported lubricant effect of high amounts of POSS in PE. Thermal ageing of $\mathrm{PE} / \mathrm{amino}-\mathrm{POSS} / \mathrm{FeSt}_{3}$ films prior to coating however led to a significant increase in adhesion. Improved physical interlocking due to increased MFI and interaction between $\mathrm{C}=\mathrm{O}$ of the blends and $\mathrm{OH}$ of paperboard can explain the adhesion improvement. The films were not brittle after thermal ageing, which makes their use in industrial packaging feasible. A mechanism explaining the role of amines during thermal oxidation of polyolefins in the presence of iron is proposed.

Keywords: polyethylene; pro-oxidant; amino-POSS; adhesion strength; carbonyl index; thermal ageing

\section{Introduction}

Polyethylene (PE) coated paperboard has been widely applied for packaging foods, beverages and pharmaceuticals because of its low cost, lightweight, non-toxicity, excellent water barrier, good mechanical properties and processability. Adhesion strength between PE and paperboard is an important property of such packaging materials [1]. The adhesion was successfully improved by introducing polar groups such as $\mathrm{CO}$ and $\mathrm{OH}$ on the surface of $\mathrm{PE}$ by oxidative treatment prior to laminating with paperboard [2,3]. Limited oxidation of PE can be provided by mixing pro-oxidant additives into PE. Pro-oxidant additives such as stearate salt of iron, cobalt or manganese are often used to improve the degradability of PE by oxidation [4-7]. The rate-limiting step in the oxidation of PE mediated by pro-oxidant additives is the decomposition of hydroperoxides. Cobalt and manganese yield sufficient thermal oxidation rates in the absence of UV light. This is however not the case with iron [8]. The decomposition of hydroperoxides in polyethylene by iron alone is not fast enough to provide rapid thermal oxidation of the polymer. However, suitable accelerators could increase the decomposition of hydroperoxides in PE and thus yield rapid thermal oxidation rates with iron as the only transition metal present. Amines are known to act as decomposer of hydroperoxides [9-12]. Amines could therefore act as suitable accelerators for iron containing prodegradants.

The application of amines in polyethylene packaging requires food contact approval and no significant colour or odour contribution from the amine component. Additionally, the amine has to be soluble or easily dispersible in the polyethylene matrix. Amines derived from fatty acids, such as stearyl amine or polymer based amines are therefore suitable candidates in order to accelerate the rate of thermal oxidation rate in polyethylene containing an iron based pro-oxidant.

Many studies have reported that the oxidation of the PE films containing pro-oxidant additive prevalently produces carbonyl $(\mathrm{C}=\mathrm{O})$ on its surface [6,13-19]. The presence of carbonyl group on PE film surface can lead to an increase in its surface polarity. When such film is laminated with paperboard, 
the adhesion can be improved due to an increase in the interfacial attractive force [20-22]. By using iron-based pro-oxidants in combination with stearyl amine or polymer based amines, it should therefore be possible to improve the adhesion of polyethylene to paperboard.

An interesting group of polymeric amines are based on polyhedral oligomeric silsesquioxane (POSS). POSS is an inorganic-organic hybrid compound with a general formula $\left(\mathrm{RSiO}_{1.5}\right)_{n}$, where $\mathrm{R}$ is an organic group, $n$ is the number of silicon atoms $(n=8,10,12)$, and a special molecular structure which is composed of an inorganic core cage and the functional organic group surrounding the core cage. The organic groups allow POSS compounds to be easily incorporated into organic polymers [23,24]. POSS has recently been used in thermoplastics and improve several properties of the materials [25-33]. In our previous work, small amounts of bio-POSS octa-(ethyl octadeca 10,13-dienoamide silsesquioxanes) was added to polyethylene (PE) and laminated with paperboard. The adhesion property of this packaging material was successfully improved when small amounts of POSS have been used. With increasing POSS amounts, the adhesion between polyethylene and paperboard was decreased, most likely due to the lubricant effect of the fatty amide based POSS [34]. We have previously based on commodities such as 3-aminopropyltriethoxy silane and fatty acids. The use of commodities in POSS synthesis provides a significantly improved cost/benefit when compared with POSS synthesis, which is based on silanes alone. A high solids air drying paint, where amide substituted POSS is an essential part of the binder system has been commercialized [35].

In this work, we chose stearyl amine to investigate the oxidation of polyethylene and polypropylene by iron/amine pro-oxidants in the first part. In the second part, we chose [(3-(11-aminoundecanoyl) amino) propane-1-] silsesquioxane (amino-POSS) to examine the effect on the adhesion strength of PE films iron/amine pro-oxidants to paperboard. Amino-POSS is due to its structure and molecular weight is likely to show lower leakage from PE compared with stearyl amine. It is therefore the preferred amine for food packaging applications.

\section{Experimental Section}

\subsection{Materials}

Low density polyethylene powder (LDPE) was provided by Normatch AS, Gjerdrum, Norway, with a melting point of $110{ }^{\circ} \mathrm{C}$, a melt flow index (MFI) of $20 \mathrm{~g} / 10 \mathrm{~min}\left(190{ }^{\circ} \mathrm{C} / 2.16 \mathrm{~kg}\right)$ and a broad molecular weight distribution. According to the manufacturer, no anti-oxidant, no technical additive, and no catalyst residue are present in this LDPE quality. The pro-oxidant additives were two masterbatches of ferric stearate $\left(\mathrm{FeSt}_{3}\right)$ in polyethylene and provided by Nor-X Industry AS (Gursken, Norway). Masterbatch A had an iron content of $0.36 \%$ and Masterbatch B had an iron content of $0.38 \%$. Both masterbatches contain stearic acid in addition to iron (III) stearate. The concentration of stearic acid in Masterbatch B is about twice as high as in Masterbatch A. Paperboard was provided by Korsnäs AB (Frövi, Sweden). Stearyl amine was purchased from Aldrich (St. Louis, MO, USA).

\subsubsection{POSS Compound}

The POSS compound is [(3-(11-aminoundecanoyl) amino) propane-1-] silsesquioxane or amino-POSS. It was was previously synthesized in our laboratory by a two-step procedure [35]. 
In the first step 3-aminopropyltriethoxy silane was converted to amino functionalized POSS by a sol-gel process. In the second step, the amine groups were further modified by an amino acid (11-aminoundecanoic acid). A typical structure of amino-POSS is shown in Figure 1.

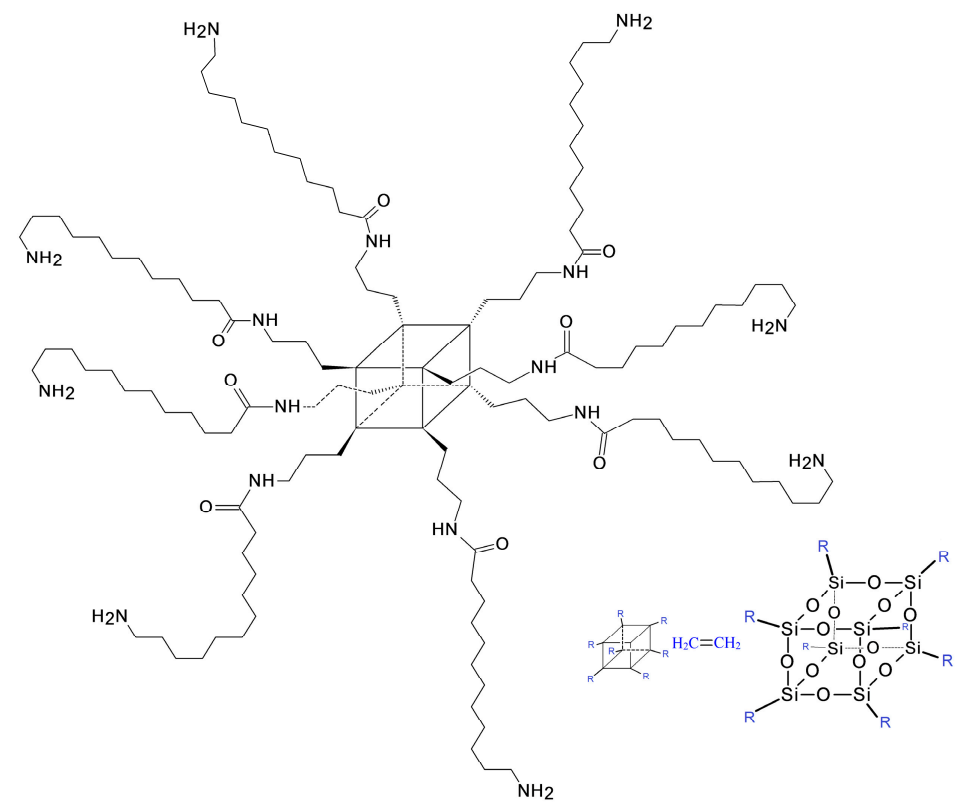

Figure 1. Typical structure of [3-(11-aminoundecanoyl amino) propane-1-] silsesquioxane (amino-POSS).

\subsubsection{Paperboard}

The paperboard has two sides with different colours: An uncoated side (brown) and a pre-coated side (white) (Figure 2a); Figure 2b shows a scanning electron microscopy (SEM) image of the uncoated side of the paperboard.
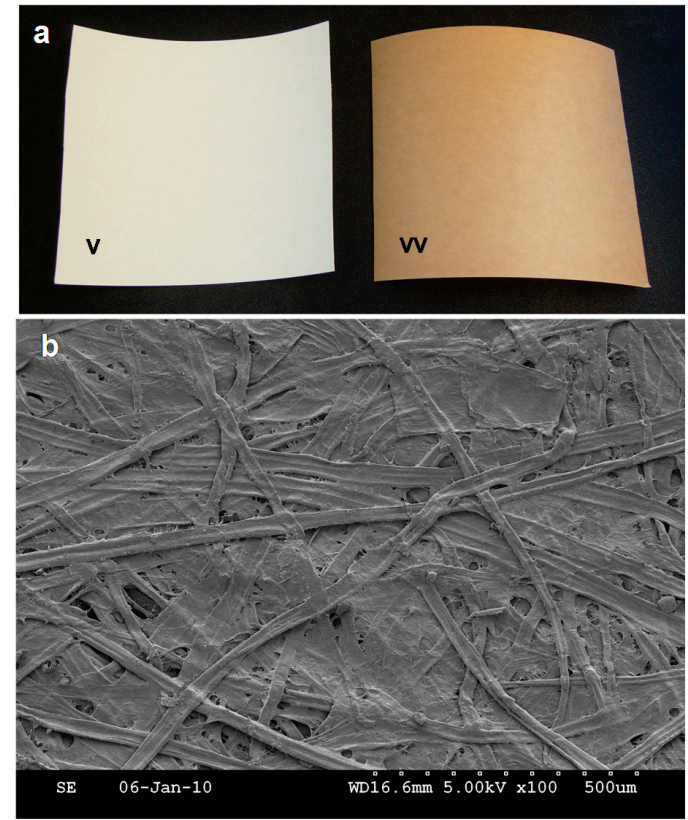

Figure 2. (a) Two sides of paperboard: (v) pre-coated side and (vv) uncoated side; (b) SEM images of the uncoated side of the paperboard. 
The uncoated side of paperboard is very rough, containing large fibres. There are many pinholes and depressions on the uncoated side of the paperboard. As can be observed, the uncoated side of paperboard is very rough, containing large fibres. The rough surface of the uncoated side of paperboard is very advantageous for polymer coating mechanical adhesion.

\subsubsection{Amine Masterbatches}

Amino-POSS was dried at $120{ }^{\circ} \mathrm{C}$ to fully remove solvent 2-butoxy ethanol which was used in its synthesis. Masterbatch $\mathrm{C}$ was prepared in a twin screw 15 cc micro extruder (DSM; Royal DSM: Heerlen, The Netherlands) including $90 \mathrm{wt} \%$ PE powder and $10 \mathrm{wt} \%$ dried amino-POSS.

Masterbatch D was prepared by the same procedure and consists of $90 \mathrm{wt} \%$ PE powder and $10 \mathrm{wt} \%$ stearyl amine.

\subsection{Sample Preparation}

\subsubsection{Preparation of PE and PP Film Containing Iron/Stearyl Amine Proxidant}

Mixtures of PP or PE and different masterbatches were compounded for three minutes in the twin screw 15 cc micro extruder (DSM MIDI2000; Xplore Instruments: Geleen, The Netherlands) at $230{ }^{\circ} \mathrm{C}$. The mixtures were compression moulded on a hydraulic compressor (Fontijne TH200; Fontijne Grotnes: Vlaardingen, The Netherlands) to a film thickness of $0.1 \mathrm{~mm}$. The temperature of the top and bottom plates of the hydraulic compressor was $180{ }^{\circ} \mathrm{C}$, the pressure was $10 \mathrm{MPa}$, and the total compression time was 5 min. Samples suitable for mechanical testing with "dumbbell" shape were prepared by using an appropriate sample puncher (Zwick \& Co. KG: Ulm, Germany). The samples had a total length of $67 \mathrm{~mm}$, a width at both ends of $14 \mathrm{~mm}$ and a width in the elongation zone of $5 \mathrm{~mm}$. Table 1 shows the composition of the different mixtures.

Table 1. Compositions of PE or PP mixtures with iron/stearyl amine proxidant ([\%] as [wt\%]; masterbatch A, B and D were described in Section 2.1).

\begin{tabular}{cccccc}
\hline Sample Mixture & $\begin{array}{c}\text { Iron Masterbatch } \\
{[\%]}\end{array}$ & $\begin{array}{c}\text { Amine Masterbatch } \\
{[\%]}\end{array}$ & $\begin{array}{c}\text { Polyolefin } \\
{[\%]}\end{array}$ & Iron [ppm] & Amine [\%] \\
\hline PP-1 & A [2\%] & 0 & PP [98\%] & 72 & 0 \\
PP-2 & A [5\%] & 0 & PP [5\%] & 180 & 0 \\
PP-4 & A [2\%] & D [10\%] & PP [88\%] & 72 & 1 \\
PP-8 & B [2\%] & 0 & PP [98\%] & 76 & 0 \\
PE-9 & B [2\%] & 0 & PE [98\%] & 76 & 0 \\
PE-12 & B [2\%] & D [10\%] & PE [98\%] & 76 & 1 \\
\hline
\end{tabular}

\subsubsection{Preparation of $\mathrm{PE}$ and $\mathrm{PE} / \mathrm{Amino}-\mathrm{POSS} / \mathrm{FeSt}_{3}$ Film}

Mixtures of PE, Masterbatch A and Masterbatch $\mathrm{C}$ were blended by melt mixing in different ratios (see Table 2) in which the content of $\mathrm{FeSt}_{3}$ was constantly kept at $0.5 \mathrm{wt} \%$ for all samples. The extrusion temperature of two processes was constantly kept at $180^{\circ} \mathrm{C}$ from hopper to die section of micro-extruder, 
the operating screw speed was controlled at $50 \mathrm{rpm} / \mathrm{min}$ and the resident time distribution profile was $5 \mathrm{~min}$. The blend product was cut into pellets.

Table 2. Compositions of PE/Amino-POSS/FeSt 3 /blends ([\%] as [wt\%], mb: masterbatch).

\begin{tabular}{ccccccc}
\hline \multirow{2}{*}{ Sample Code } & \multirow{2}{*}{$\begin{array}{c}\text { PE (pellet) } \\
(\mathbf{w t} \%)\end{array}$} & $\begin{array}{c}\text { mb A } \\
(\mathbf{w t} \%)\end{array}$ & \multirow{2}{*}{$\begin{array}{c}\text { mb C } \\
(\mathbf{w t} \%)\end{array}$} & \multicolumn{3}{c}{ Composition } \\
\cline { 5 - 7 } & & & & PE [\%] & Fe [ppm] & amino-POSS [\%] \\
\hline PE & 100 & 0 & 0 & 100 & 0 & 0 \\
90505 & 90 & 5 & 5 & 99 & 180 & 0.5 \\
85510 & 85 & 5 & 10 & 98.5 & 180 & 1 \\
80515 & 80 & 5 & 15 & 98 & 180 & 1.5 \\
\hline
\end{tabular}

Thin films of PE and the blends were prepared by compression moulding pure PE powder and PE/amino-POSS/FeSt 3 pellets on a hydraulic compressor (Fontijne TH200; Fontijne Grotnes: Vlaardingen, The Netherlands), respectively. The film thickness was $0.1 \mathrm{~mm}$. The temperature of the top and bottom plates of the hydraulic compressor was $180{ }^{\circ} \mathrm{C}$, the pressure was $10 \mathrm{MPa}$, and total time was 5 min.

\subsubsection{Thermal Ageing of the Film}

The dumbbell shape samples with the compositions from Table 1 were thermally exposed at $80{ }^{\circ} \mathrm{C}$ for 5 or 10 days in an air circulation oven (Termaks 4057; Termaks AS: Bergen, Norway).

The films with the compositions from Table 2 were thermally exposed at $70{ }^{\circ} \mathrm{C}$ for 3 or 6 days in an air circulation oven (Termaks 4057; Termaks AS: Bergen, Norway).

\subsubsection{Coating on Paperboard}

The films with the compositions from Table 2 and the respective thermal ageing were coated on paperboard by compression moulding coating on a hydraulic compressor (Fontijne TH200; Fontijne Grotnes: Vlaardingen, The Netherlands). The coating conditions were kept constant at the pressure of $10 \mathrm{MPa}$ and the temperature of the top/bottom plate of $200^{\circ} \mathrm{C} / 20^{\circ} \mathrm{C}$. The coating process was complete after cooling down two plates of the compressor to the room temperature by opening cold water system. The coating time was 3 min.

\subsection{Characterization}

\subsubsection{Tensile Testing of Dumbbell Shape Samples and Respective Thermal Ageing}

The mechanical properties of the dumbbell shape samples were determined by tensile testing according to ISO 527-1 on the device Zwick-Z250 (Zwick International: Ulm, Germany). At least 5 specimens of each film were prepared for tensile testing. The test was run at the speed of $50 \mathrm{~mm} / \mathrm{min}$ and room temperature. 


\subsubsection{ATR-FTIR and Carbonyl Index (CI)}

Attenuated total reflection Fourier transform infrared (ATR-FTIR) was performed in a PerkinElmer FTIR device (Spectrum One) at room temperature in the wave number range $650-4000 \mathrm{~cm}^{-1}$, at a resolution of $4 \mathrm{~cm}^{-1}$, and scan number of 4 . The result spectrum was reported as absorbance unit (a.u.).

Results from ATR-FTIR analysis were used to determine the carbonyl index (CI). CI is a measurement of the amount of carbonyl compounds formed during the thermal oxidation and is calculated as the ratio of the absorbance (A) of carbonyl peak in the region $1700-1780 \mathrm{~cm}^{-1}$ and the $\mathrm{CH}_{2}$ scissoring peak at $1464 \mathrm{~cm}^{-1}[13-15]$ :

$$
C I=\frac{A_{1700-1780 \mathrm{~cm}^{-1}}}{A_{1464 \mathrm{~cm}^{-1}}}
$$

\subsubsection{Adhesion Measurement}

A T-peel test was performed on a tensile tester (Zwich-Z250; Zwick International: Ulm, Germany) to determine the adhesion of our samples. At least five $T$-type specimens (200 $\mathrm{mm}$ in length and $15 \mathrm{~mm}$ in width) were prepared for each sample by using JDC-15 mm-10 in sample cutter (Thwing-Albert, West Berlin, NJ, USA). The polymer coating was peeled at the speed of $30 \mathrm{~mm} / \mathrm{min}$. and over a length of $150 \mathrm{~mm}$.

The adhesion value was determined as:

$$
\text { Adhesion }=\frac{\text { Peel force }}{\text { Width }}(\mathrm{N} / \mathrm{m})
$$

The adhesion strength of the sample was calculated as the average of five adhesion values that corresponded to five specimens.

\subsubsection{Melt Flow Index}

The effect of amino-POSS content on melt flow of PE was monitored by melt flow index (MFI) method on a melt flow apparatus, Davenport 3/80. The materials were fully loaded into a cylinder of MFI device and then melted at temperature of $190{ }^{\circ} \mathrm{C}$. Pre-heating time and extrudate time were set at 5 and $10 \mathrm{~min}$. MFI was expressed as the mass of the material per 10 min extruded through the die of $2.09 \mathrm{~mm}$ in diameter and $8 \mathrm{~mm}$ in length, under the standard weight of $2.16 \mathrm{~kg}$ :

$$
M F I=\frac{\text { Average extrudate weight }}{\text { Time }}(\mathrm{g} / 10 \mathrm{~min})
$$

\subsubsection{Mechanical Properties}

The mechanical properties of the film were determined by tensile testing according to ISO 527-1 on the device Zwick-Z250. Test specimens were cut from the film with "dumbbell" shape. At least 5 specimens of each film were prepared for tensile testing. The test was run at the speed of $50 \mathrm{~mm} / \mathrm{min}$ and room temperature. 


\section{Results and Discussion}

\subsection{Polyolefin Samples with Iron Pro-Oxidant and Stearyl Amine Accelerator}

Tensile Properties after Different Periods of Ageing

The tensile properties of PP and PE samples with iron pro-degradant and stearyl amine accelerator are shown in Tables 3 and 4. The results show clearly the influence of the stearyl amine accelerator in PP-4 and PE-12 compared with the reference sample mixtures PP-1 and PE-9. The extreme brittleness of PP-4 after 10 days at $80^{\circ} \mathrm{C}$ shows that the stearyl amine accelerators can yield rapid thermal oxidation rates of polyolefins with iron as the only transition metal present. Increase of iron concentration does not give a significant increase in the thermal oxidation rate.

Comparison of PP-1 and PP-8 shows that the increased content of stearic acid (about double amount in PP-1 compared to PP-1) leads to a reduced oxidation rate.

Table 3. Elongation at break [\%] after 0,5 and 10 days of ageing at $80^{\circ} \mathrm{C}$.

\begin{tabular}{cccc}
\hline Sample Mixture & 0 Days & 5 Days & 10 Days \\
\hline PP-1 & $652 \pm 113$ & $210 \pm 165$ & $8 \pm 5$ \\
PP-2 & $536 \pm 261$ & $426 \pm 367$ & $13 \pm 13$ \\
PP-4 & $868 \pm 84$ & $270 \pm 286$ & $<1$ (extremely brittle) \\
PP-8 & $669 \pm 242$ & $720 \pm 155$ & $569 \pm 291$ \\
PE-9 & $614 \pm 311$ & $355 \pm 361$ & $610 \pm 331$ \\
PE-12 & $797 \pm 103$ & $765 \pm 166$ & $11 \pm 10$ \\
\hline
\end{tabular}

Table 4. Tensile strain at break $[\mathrm{MPa}]$ after 0,5 and 10 days of ageing at $80{ }^{\circ} \mathrm{C}$.

\begin{tabular}{cccc}
\hline Sample Mixture & 0 Days & 5 Days & 10 Days \\
\hline PP-1 & $27.1 \pm 2.1$ & $29.7 \pm 0.7$ & $22.2 \pm 2.0$ \\
PP-2 & $27.0 \pm 1.2$ & $27.3 \pm 2.7$ & $21.7 \pm 5.1$ \\
PP-4 & $33.5 \pm 2.4$ & $28.7 \pm 2.6$ & $<2$ (extremely brittle) \\
PP-8 & $30.3 \pm 1.6$ & $32.7 \pm 3.1$ & $28.5 \pm 1.5$ \\
PP-9 & $28.7 \pm 3.6$ & $30.1 \pm 2.5$ & $28.4 \pm 1.3$ \\
PP-12 & $29.7 \pm 6.9$ & $27.9 \pm 7.7$ & $12.7 \pm 3.0$ \\
\hline
\end{tabular}

The results also show that processing of the mixtures at the applied conditions is feasible. Elongation at break of several hundred percent clearly indicate that the samples have not been degraded during processing.

\subsection{PE Samples with Iron Pro-Oxidant and Amin-POSS Accelerator}

\subsubsection{ATR-FTIR Studies}

The ATR-FTIR is a useful technique for characterizing the surface of the material. In this work, the ATR-FTIR analyses were performed on starting materials and blends from Table 2. The result is shown in Figure 3. The study of Rao was used for the interpretation of our ATR-FTIR spectra [36]. 
The main peaks of PE are $2920 \mathrm{~cm}^{-1}$ and $2851 \mathrm{~cm}^{-1}\left(\mathrm{CH}_{2}\right.$ stretching), $1471 \mathrm{~cm}^{-1}$ and $1430 \mathrm{~cm}^{-1}$ $\left(\mathrm{CH}_{2}\right.$ bending), $720 \mathrm{~cm}^{-1}\left(\mathrm{CH}_{2}\right.$ rocking). The main peaks of amino-POSS are: the absorption peaks at $3287 \mathrm{~cm}^{-1}$ and $3074 \mathrm{~cm}^{-1}$ are assigned to the hydrogen-bonded $\mathrm{N}-\mathrm{H}$ stretching $(\mathrm{N}-\mathrm{H} \ldots \mathrm{O}=\mathrm{C})$; two bands appear at $1640 \mathrm{~cm}^{-1}$ and $1548 \mathrm{~cm}^{-1}$ are assigned to amide I (carbonyl $\mathrm{C}=\mathrm{O}$ ) and amide II (mixed vibration involving $\mathrm{N}-\mathrm{H}$ in-plane bending and $\mathrm{C}-\mathrm{N}$ stretching), respectively. Normally, the intensity of amide I is stronger than that of amide II. A band at $1271 \mathrm{~cm}^{-1}$ is amide III (mixed vibration of C-N stretching and $\mathrm{N}-\mathrm{H}$ bending). Two strong and broad bands at $1119 \mathrm{~cm}^{-1}$ and $1028 \mathrm{~cm}^{-1}$ exhibit Si-O-Si stretching of the cubic $\mathrm{Si}_{8} \mathrm{O}_{12}$ structure. The spectrum of masterbatch $\mathrm{FeSt}_{3} / \mathrm{PE}$ shows two strong peaks near 2920 and $2851 \mathrm{~cm}^{-1}\left(\mathrm{CH}_{2}\right.$ stretching), a strong and sharp peak at $1700 \mathrm{~cm}^{-1}$ (carbonyl $\mathrm{C}=\mathrm{O}$ of ester group), $1471 \mathrm{~cm}^{-1}$ ( $\mathrm{CH}_{2}$ bending), $1430 \mathrm{~cm}^{-1}$ (stretching vibration of $\mathrm{C}-\mathrm{O}$ group). The band characteristic to the symmetric stretching vibration of the group COO appears at $1355 \mathrm{~cm}^{-1}$. The band from $1298 \mathrm{~cm}^{-1}$ can be assigned to the $\mathrm{C}-\mathrm{COO}$ vibrations. The interpretation of ATR-FTIR spectrum of $\mathrm{FeSt}_{3} / \mathrm{PE}$ is similar to that in other studies concerning the spectrum of carboxylate group [37-39].

As can be observed in Figure 3, the main characteristics of $\mathrm{PE}$, amino-POSS and $\mathrm{FeSt}_{3}$ were introduced into the spectra of the blends 90505, 85510, and 80515. However, the introduced peaks are very small due to the low concentration of amino-POSS and $\mathrm{FeSt}_{3}$ in the blends.

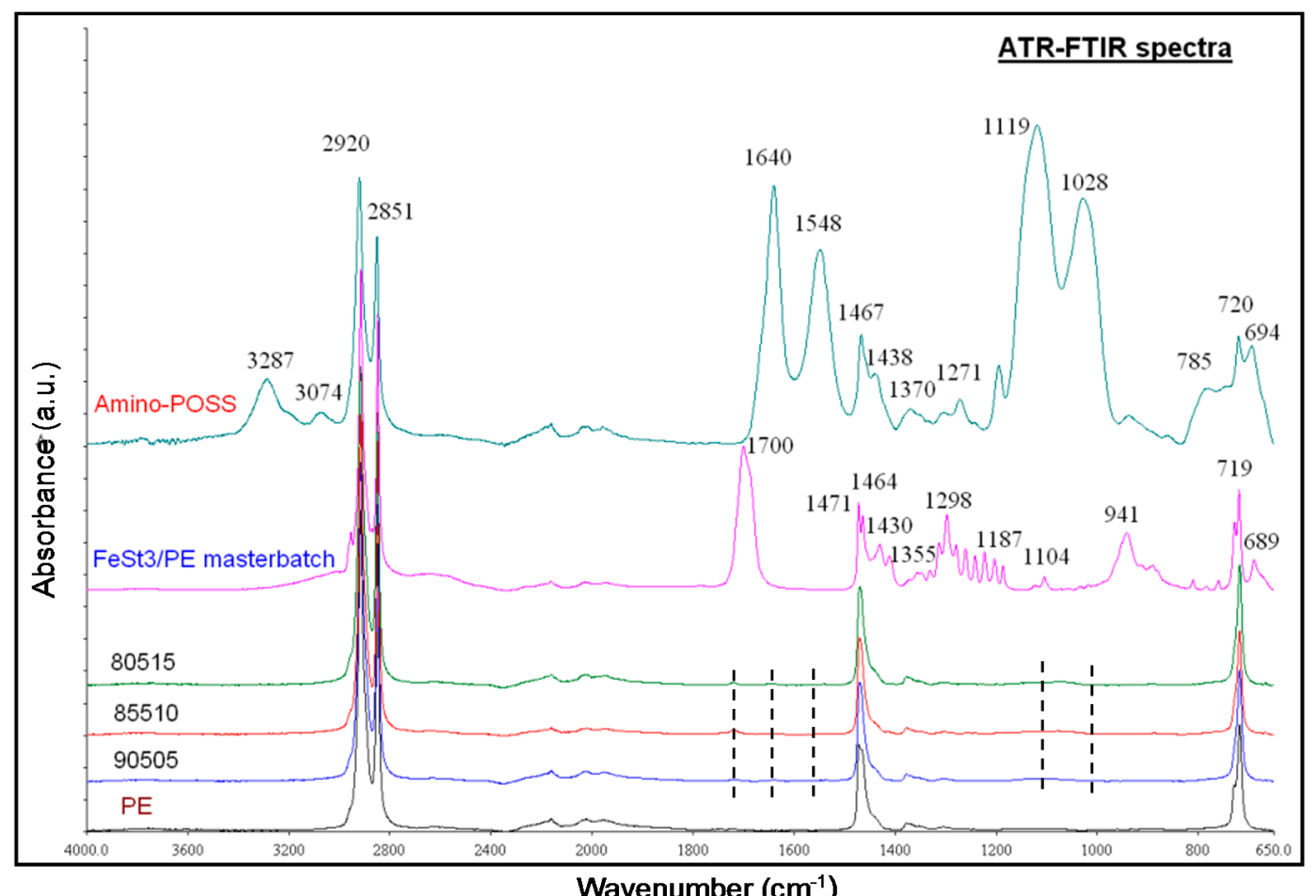

Figure 3. FTIR spectra of PE/amino-POSS/FeSt 3 blends.

\subsubsection{Thermal Ageing}

The thermally aged films were characterized by ATR-FTIR and the result is shown in Figure 4. All spectra of the aged film exhibit the absorption band in the region $1700-1780 \mathrm{~cm}^{-1}$ which is assigned to carbonyl $(\mathrm{C}=\mathrm{O})$ groups, as determined by the overlapping bands corresponding to ester $\left(1737 \mathrm{~cm}^{-1}\right)$, ketone (1715 and $1717 \mathrm{~cm}^{-1}$ ). These bands are evidence for the formation of different oxidized products similar to those found in other studies involving the oxidation of PE [10,13-15]. If comparing the 
intensity of $\mathrm{C}=\mathrm{O}$ of the film after thermal ageing and that before ageing, it increases with increasing the ageing time.

The oxidation level of $\mathrm{PE} /$ amino-POSS/FeSt 3 can be evaluated by the carbonyl index (CI). Figure 5 shows the $\mathrm{CI}$ of $\mathrm{PE}$ and $\mathrm{PE} / \mathrm{amino}-\mathrm{POSS} / \mathrm{FeSt}_{3}$ film before and after thermal ageing. In general, the $\mathrm{CI}$ is increased with increasing the ageing time. The increase in CI of the pure PE film was negligible. The CI of the film containing pro-oxidant was higher than that of the PE film, emphasizing the degrading effect of $\mathrm{FeSt}_{3}$. In fact, there was slight increase in the CI of the aged film 85510, 80515 whereas the CI of the film 90505 was substantially increased with increasing the ageing time. It strongly reflects that the oxidation level of the blend was limited when amino-POSS content is increased. Oxidative degradation of the blends can be detected by FT-IR even if the degree of oxidative degradation is very limited.

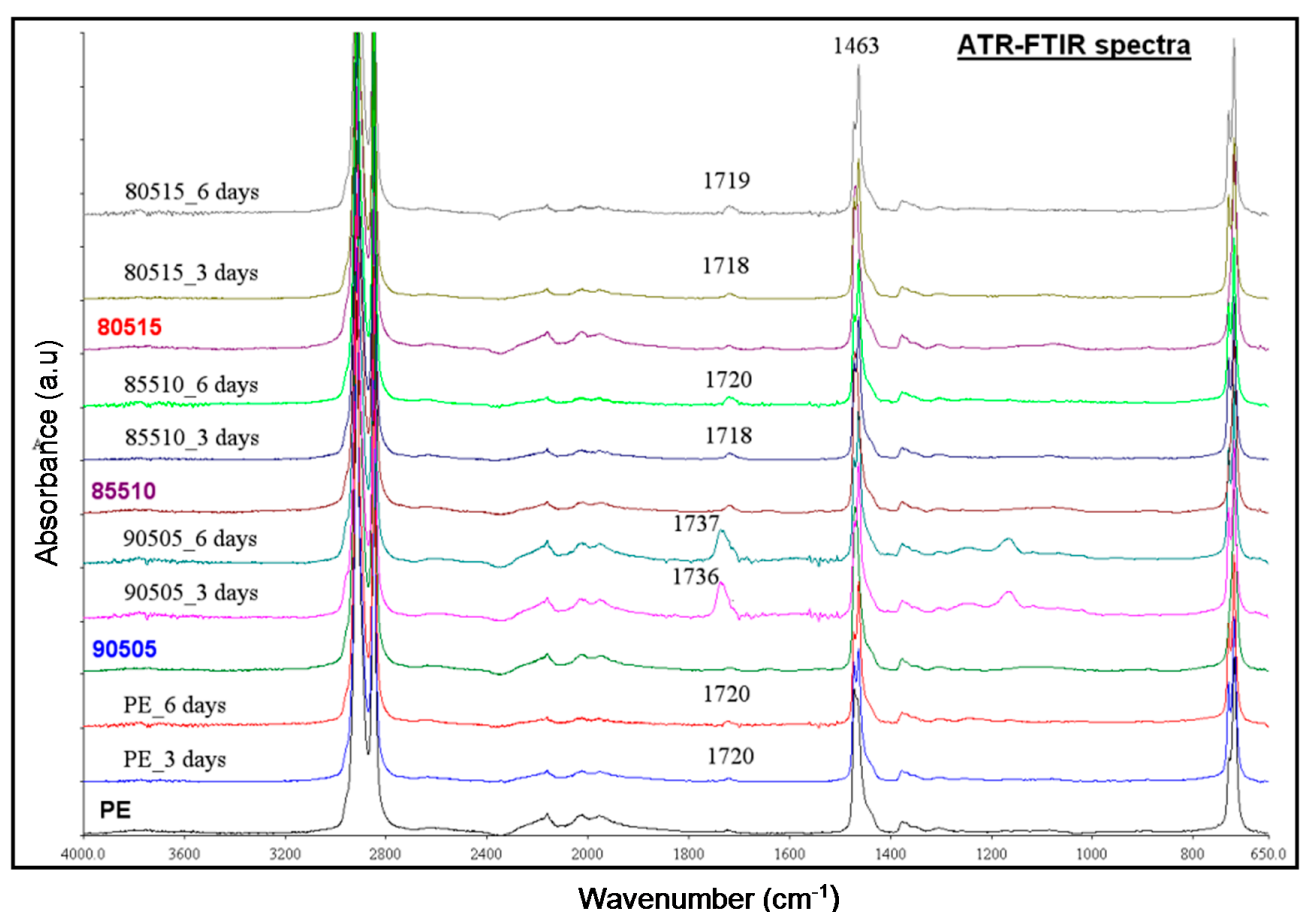

Figure 4. ATR-FTIR spectra of the blends before and after thermal aging.

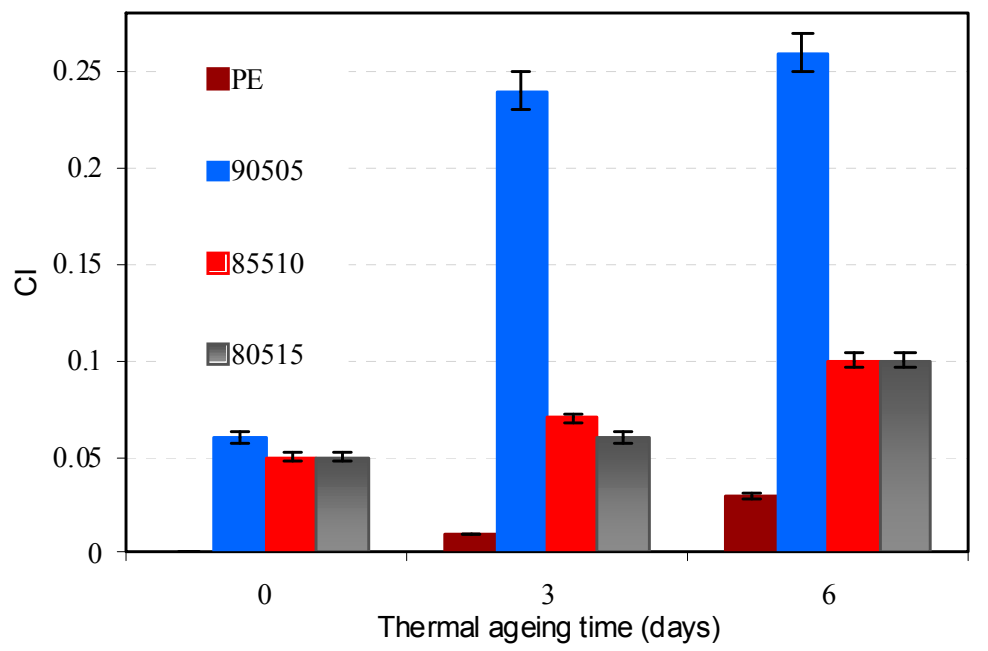

Figure 5. Carbonyl index (CI) of PE and PE/amino-POSS/FeSt film. $_{3}$ 


\subsubsection{Melt Flow Index (MFI)}

Melt flow index is an inverse measure of the melt viscosity. The higher an MFI, the more easily the polymer flows under the test conditions. Knowing the MFI of a certain polymer is vital for controlling its processing. The melt flow properties of our PE/amino-POSS/FeSt 3 blends were determined by MFI testing and are shown in Figure 6.

Neat PE showed a decrease in the MFI after thermal ageing. It suggests that some cross-linking might have formed by oxidative degradation of PE during thermal ageing [38]. The MFI of the $\mathrm{PE} /$ amino-POSS/FeSt 3 blends were decreased with increasing amino-POSS content. However, after thermal ageing in air circulation oven, the MFI of the blends containing pro-oxidant additives were increased with increasing the ageing time. In fact, the increase in the MFI of the blends was negligible after three days but it was considerable after six days of air oven ageing. The blend 90505 after being thermally aged for six days exhibited the highest MFI value. It indicates that the presence of pro-oxidant leads to a chain scission of PE during thermal ageing so as to cause a change in the melt indices. The MFI of the aged blends were also decreased with increasing amino-POSS content. As determined above, the CI of the sample 90505 was much higher than that of 85510 and 80515 . It indicates that the PE chain scission might be hindered by increasing amino-POSS content.

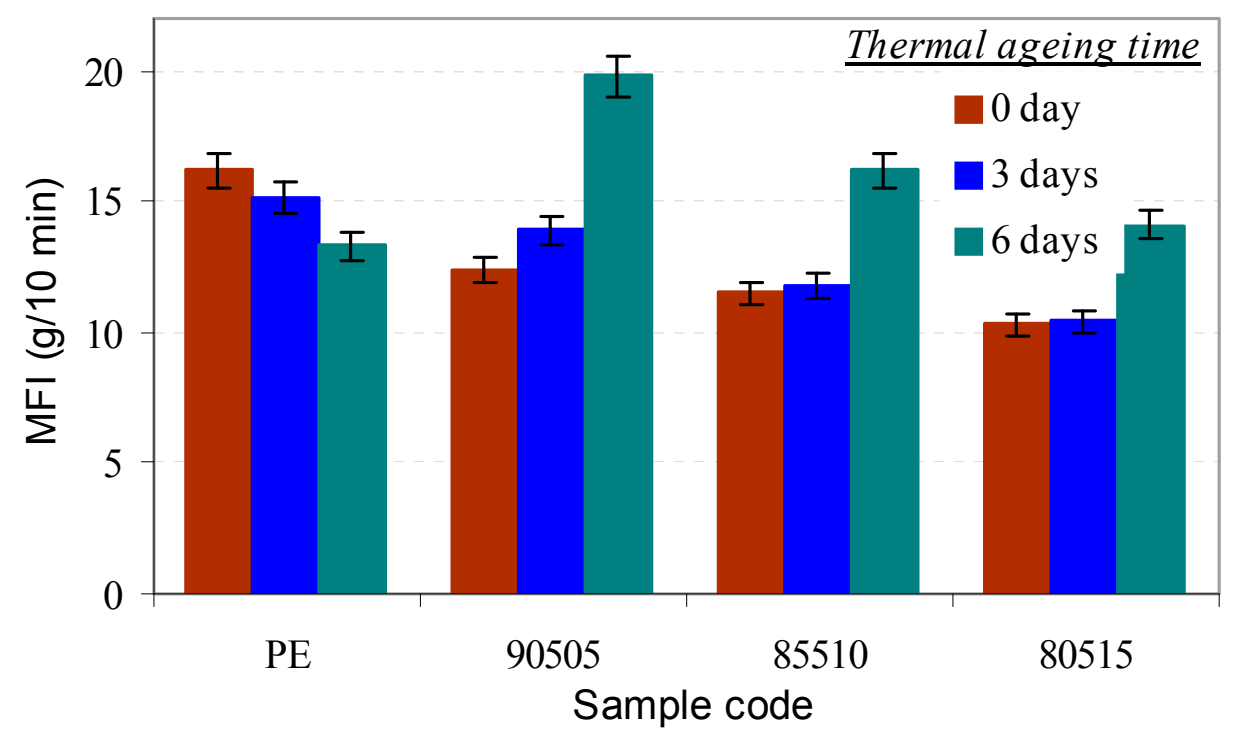

Figure 6. Melt flow index of $\mathrm{PE}$ and $\mathrm{PE} / \mathrm{amino}-\mathrm{POSS} / \mathrm{FeSt}_{3}$ blends after thermal aging.

\subsubsection{Mechanical Properties}

The mechanical properties of $\mathrm{PE}$ and $\mathrm{PE} / \mathrm{amino}-\mathrm{POSS} / \mathrm{FeSt}_{3}$ films were determined by tensile testing. Figure 7 illustrates the effect of thermal exposure on the tensile yield strength $\left(\sigma_{Y}\right)$ and elongation at break $\left(\varepsilon_{\mathrm{B}}\right)$ of films, respectively. It can be recognized that $\sigma_{\mathrm{Y}}$ of PE/amino-POSS/FeSt 3 blend films were slightly decreased with increasing amino-POSS content (Figure $7 \mathrm{a}$ ), while $\varepsilon_{\mathrm{B}}$ was moderately decreased (Figure $7 \mathrm{~b}$ ). The decrease in $\sigma_{\mathrm{Y}}$ and $\varepsilon_{\mathrm{B}}$ might be due to the presence of amino-POSS aggregates within the PE/amino-POSS/FeSt 3 blends [34].

When the films were thermally aged, their mechanical properties were decreased with the ageing time. The tensile yield strength of PE and PE/amino-POSS/FeSt ${ }_{3}$ films was moderately decreased after 
three days of thermal ageing but hardly changed afterwards. The elongation at break of pure PE film dropped to $261 \%$ and $128 \%$ from an initial figure of $265 \%$ after three and six days of thermal ageing, respectively. However, the effect of thermal exposure on the $\varepsilon_{\mathrm{B}}$ of the blend films was small. $\varepsilon_{\mathrm{B}}$ of all the aged films was more than $50 \%$ after thermal ageing.
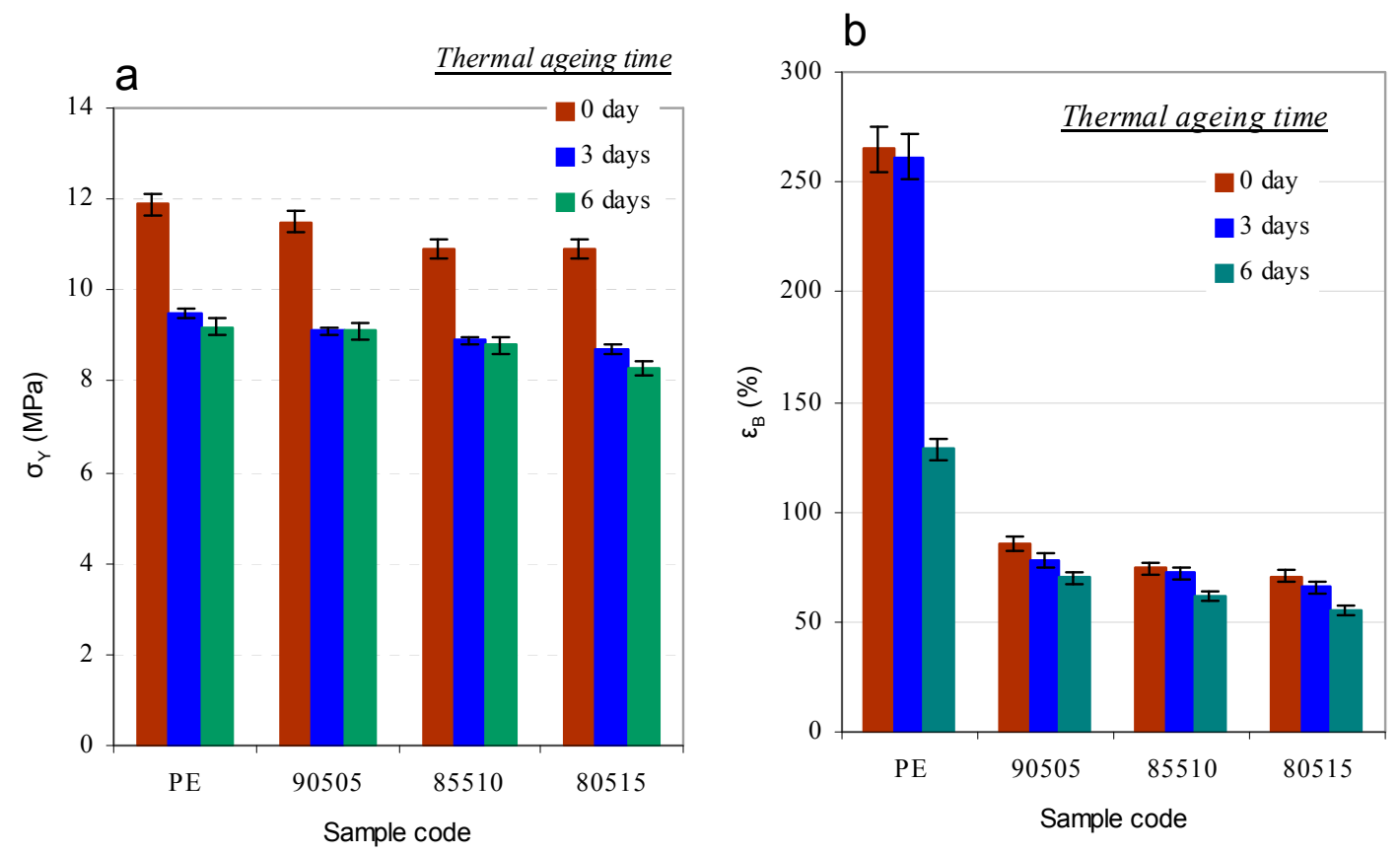

Figure 7. Effect of thermal aging on the tensile yield strength (a), an elongation at break (b) of PE/amino-POSS/FeSt ${ }_{3}$ film.

As identified above, thermal ageing of PE/amino-POSS/FeSt 3 films led to a formation of carbonyl groups. Increasing the ageing time produced an increase in the intensity of carbonyl peak, as determined by the CI. It indicates that the polymer chains were cleaved to give a rise in carbonyl groups. Due to the cleavage of polymeric chains, $\varepsilon_{\mathrm{B}}$ also decreased as the ageing time was increased. The elongation at break was the most suitable parameter to quantify the degradation. The result of mechanical properties demonstrates that the film was degraded by thermal oxidation.

The incorporation of amino-POSS into the blends led to a larger reduction on $\sigma_{\mathrm{Y}}$ and $\varepsilon_{\mathrm{B}}$ of the blend films (Figure 6b). Furthermore, the presence of amino-POSS reduced the oxidation level of the blends, as the CI reduced when increasing amino-POSS content in the blends (Figure 4). It reflects that amino-POSS has an influence on the effectiveness of the pro-oxidant $\mathrm{FeSt}_{3}$.

\subsubsection{Adhesion to Paperboard}

Adhesions of $\mathrm{PE}$ and PE/amino-POSS/FeSt 3 blends to paperboard are shown in Figure 8. As can be seen, the adhesion strength was decreased with increasing amino-POSS content while $\mathrm{FeSt}_{3}$ content was kept constantly at $0.5 \mathrm{wt} \%$. The standard deviation is relatively small for all our samples (below $50 \mathrm{~N} / \mathrm{m}$ ). It reflects that the adhesion strength of the blends to paperboard is equally distributed. The reduction in the adhesion with increasing amino-POSS content may be caused by a lubricant effect of the POSS compound, as previously reported [34]. 
When the film was thermally treated in a circulation oven, its adhesion to paperboard was altered. The adhesion strength of the aged PE to the paperboard was decreased. It was probably due to a reduction in the melt flow property of the aged PE, as determined by the MFI testing. Whereas, when $\mathrm{PE} / \mathrm{amino}-\mathrm{POSS} / \mathrm{FeSt}_{3}$ blends were thermally treated prior to coating, the adhesion to the paperboard was increased with an increase in the ageing time. Remarkably, the adhesion was improved approx. $30 \%$ by thermal treating the blend 90505 before coating on paperboard. The MFI test shows that the flowability of the blends increased with increasing the ageing time. In this case, physical interlocking could cause an enhancement in adhesion of the blends to paperboard.

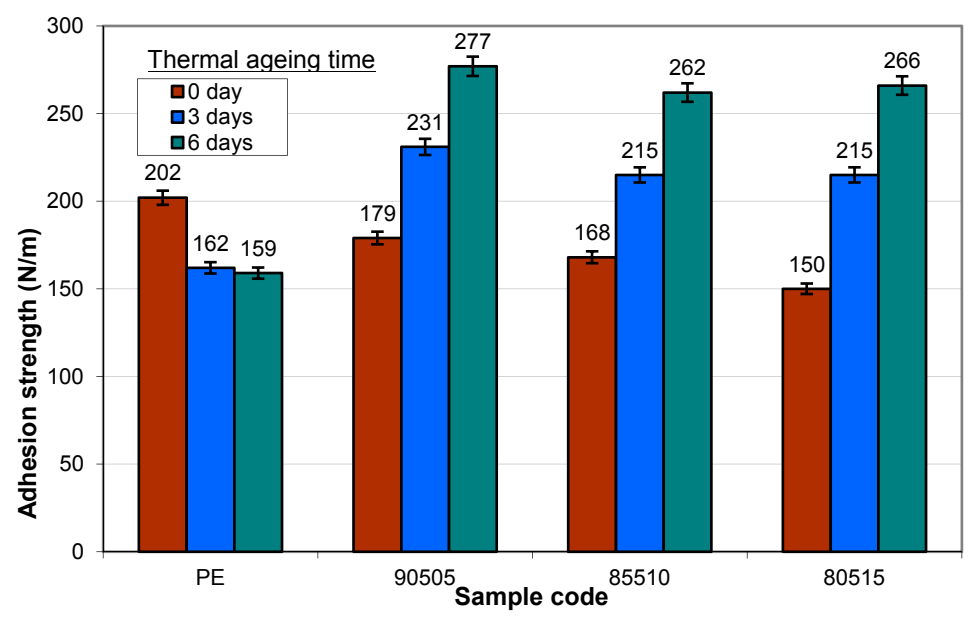

Figure 8. Adhesion strength of PE/amino-POSS/FeSt 3 blends to paperboard.

As identified by ATR-FTIR, there was a carbonyl group which formed on the surface of the $\mathrm{PE} / \mathrm{amino}-\mathrm{POSS} / \mathrm{FeSt}_{3}$ films. Such groups can interact with hydroxyl groups $(\mathrm{OH})$ of the paperboard to form hydrogen bonds, as discussed previously [34]. The formation of interfacial hydrogen bonding interaction can lead to an enhancement in the adhesion of PE/amino-POSS/FeSt ${ }_{3}$ films to paperboard.

Thermal ageing and ATR-FTIR have not been done simultaneously. Sometimes, ATR-FTIR measurement has been done several days after ageing ended. The results prove that the oxidation is stable and is not eliminated due to storage. This is a big advantage compared to flame treatment or corona treatment, which lasts less than $30 \mathrm{~min}$ and has to be applied in-line with packaging material manufacturing.

\subsubsection{Proposed Mechanism for Oxidation of PE by Iron Pro-Oxidant and Amine Accelerator}

The initial steps for the oxidative degradation of polyolefins are well known:

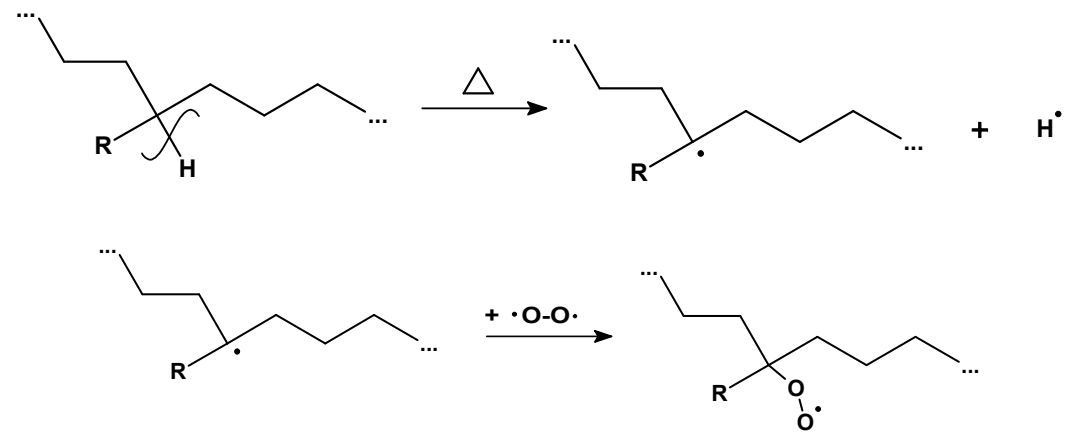


Stearic acid facilitates the transformation of peroxy radicals into hydroperoxides, which is mediated by oxidation of $\mathrm{Fe}^{2+}$ to $\mathrm{Fe}^{3+}$ :

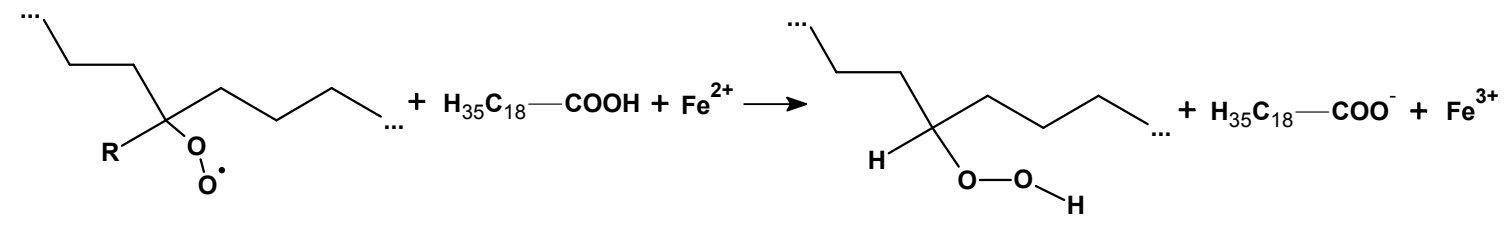

The oxidation of $\mathrm{Fe}^{2+}$ to $\mathrm{Fe}^{3+}$ is also crucial for the transformation of hydroperoxides into alkoxy radicals:

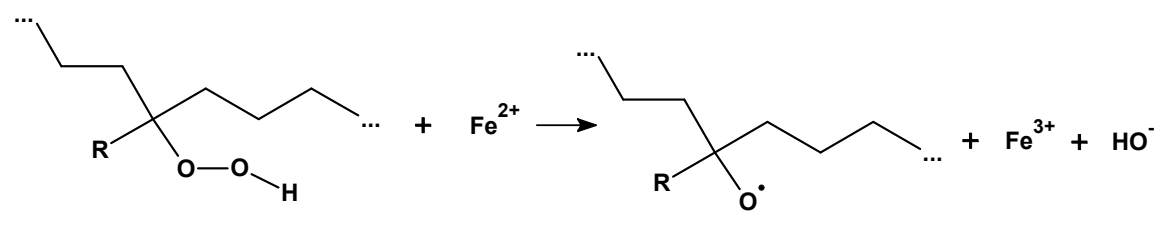

Alkoxy radicals undergo easily a bond cleavage that leads to oxidized polymer chains. Repeated chain scission in the polymer main chain leads to brittle materials.
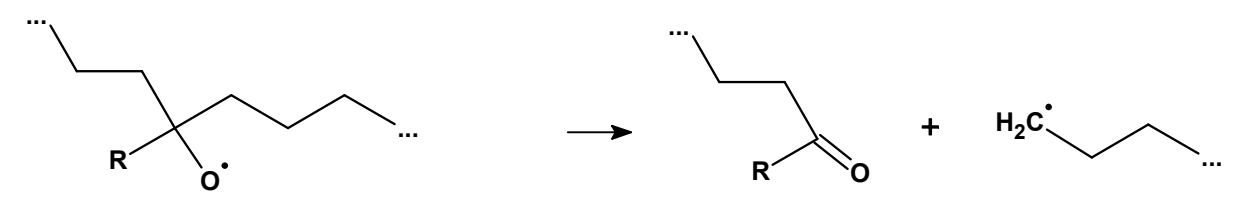

The role of the amine accelerator is on the one hand the regeneration of the iron catalyst reduction of $\mathrm{Fe}^{3+}$ to $\mathrm{Fe}^{2+}$ :

$$
\begin{gathered}
\mathrm{Fe}^{3+}+\mathrm{H}_{35} \mathrm{C}_{18}-\mathrm{NH}_{2}+\mathrm{HO}^{-} \longrightarrow \mathrm{Fe}^{2+}+\mathrm{H}_{35} \mathrm{C}_{18}-\mathrm{NH}^{-}+\mathrm{H}_{2} \mathrm{O} \\
\mathrm{H}_{35} \mathrm{C}_{18}-\mathrm{NH}^{\cdot}+\mathrm{H}^{\cdot} \longrightarrow \mathrm{H}_{35} \mathrm{C}_{18}-\mathrm{NH}_{2}
\end{gathered}
$$

On the other hand, the amine can directly lead to transformation of hydroperoxides into alkoxy radicals:

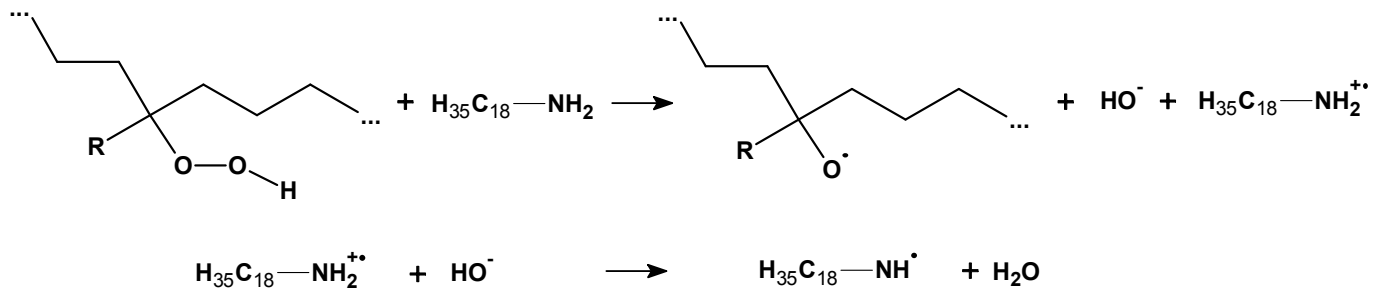

Amine radicals are capable of initiating radical formation in the PE backbone while the amine is regained.

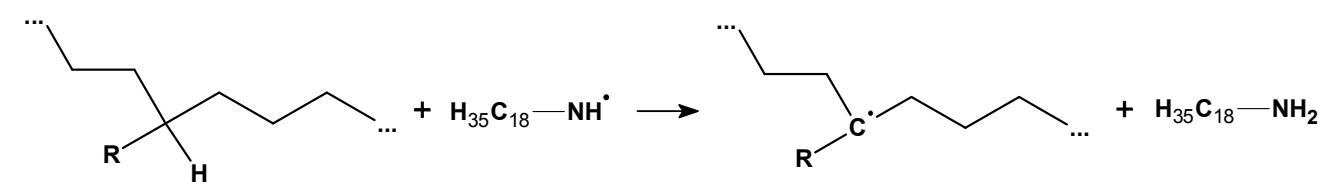


Other reactions with the involved radicals and substances may occur, such as the combination of radicals and the reaction of radicals with different substrates. However the proposed mechanism explains the role of amine as accelerator together with an iron pro-oxidant due to acceleration of rate limiting steps. Especially, the regeneration of iron after transformation of peroxy radicals into alkoxy radicals is an important role of the amine. The proposed mechanism is in good compliance with the experimental results.

\section{Conclusions}

Stearyl amine and amino-POSS have been used together with ferric stearate $\left(\mathrm{FeSt}_{3}\right)$ in order to accelerate the thermal oxidation of polyolefins. Significant acceleration in thermal oxidation of polypropylene and polyethylene compared to reference materials without amine has been obtained. A mechanism has been proposed which can explain the role of amines during thermal oxidation of polyolefins. The regeneration of the iron catalyst seems to be an important role of the amine. Amino-POSS has been chosen for food packaging applications due to its expected lower leakage from PE compared with stearyl amine.

The pro-oxidant additive ferric (III) stearate and amino-POSS were introduced into PE by using a melt mixing method. The effect on the adhesion strength of the resulting PE films to paperboard has been examined. The oxidative degradation and melt flow properties of the PE were obviously affected by amine-POSS. Small amounts of amino-POSS resulted in a fast increase of the carbonyl index showing a fast oxidation. Increasing amino-POSS content did not further accelerate the oxidation. This behaviour is in good compliance with the main role of amino-POSS as regenerator of the iron catalyst. The mechanical properties (tensile yield strength and elongation at break) of $\mathrm{PE} / \mathrm{amino}-\mathrm{POSS} / \mathrm{FeSt}_{3}$ films decreased, but the films still remained flexible. When PE/amino-POSS/FeSt 3 films were compression moulding coated on paperboard, the adhesion strength was decreased with increasing amino-POSS content which is in good compliance with earlier findings. The adhesion was however increased when such films were treated at $70{ }^{\circ} \mathrm{C}$ prior to coating. The adhesion improvement was probably due to the interaction between $\mathrm{OH}$ groups of paperboard and $\mathrm{C}=\mathrm{O}$ groups of $\mathrm{PE} / \mathrm{amino}-\mathrm{POSS} / \mathrm{FeSt}_{3}$ blends. The physical interlocking due to reduced melt viscosity could be considered as a reason for adhesion improvement. Processing of coated paperboard in state-of-the-art packaging machines should be feasible.

From a commercial point of view, it is important to remember that amino-POSS is applied in small quantities and its manufacturing is based on commodities. On the other hand, the six-day thermal aging would significantly increase the costs of the final cardboard. Further work should be done in order to utilize the observed accelerated oxidation within existing packaging manufacturing processes. The persistence of the oxidation could be used in cases were short storage of films prior to lamination are part of the packaging manufacturing process. Amount of amino-POSS used, storage time and storage temperature should of course be optimized for a given process. This has been beyond the scope of the present work. In contrast to earlier work, where fatty amide substituted POSS has been used, the adhesion improvement has been obtained by an oxidation process. This aspect could open up the opportunity for application in different materials and possible enhancement of other properties such as oxygen scavenging or anti-microbial surfaces. 


\section{Acknowledgments}

This study has been financially supported by the Research Council of Norway and the industrial partners Dynea AS, Elopak AS, Forestia AS, Peterson Linerboard AS, Korsnäs AB, and Södra Cell AB in the KMB project (SustainBarrier 182619). The authors are grateful for the materials received from Normatch AS (Gjerdrum) and Nor-X Industry AS (Gursken), Norway; and Korsnäs AB, Frövi, Sweden.

\section{Author Contributions}

This paper has been done by Tuan-Anh Nguyen, PhD Candidate from Department of Chemical Engineering, Norwegian University of Science and Technology (NTNU). The scientific work has been mainly supervised by Senior Scientist, Ferdinand Männle (Synthesis and Properties, SINTEF Materials and Chemistry, Oslo, Norway) and Øyvind Weiby Gregersen (The faculty of Natural Sciences and Technology, NTNU, Trondheim, Norway).

\section{Conflicts of Interest}

The authors declare no conflict of interest.

\section{Abbreviations}

Amino-POSS, [3-(11-aminoundecanoyl) amino) propane-1-] silsesquioxane; ATR-FTIR, Attenuated Total Reflectance Fourier transform infrared spectroscopy; CI, Carbonyl index; $\mathrm{FeSt}_{3}$, Ferric stearate; MFI, Melt flow index; PE, Polyethylene; mb, masterbatch.

\section{References}

1. Kemppi, A. Studies on the Adhesion between Paper and Low Density Polyethylene; Åbo Akademi University: Åbo, Finland, 1997; p. 39.

2. Westerlind, B.; Larsson, A.; Rigdahl, M. Determination of the degree of adhesion in plasma-treated polyethylene/paper laminates. Int. J. Adhes. Adhes. 1987, 7, 141-146. [CrossRef]

3. Kaplan, S.L.; Rose, P.W. Plasma surface treatment of plastics to enhance adhesion. Int. J. Adhes. Adhes. 1991, 11, 109-113. [CrossRef]

4. Nikos, K. Oxobiodegradable Polyolefins: Their Biodegradation and Recycling. Available online: http://eurasia12.uoi.gr/Abstracts_pdf/(4)\%20Environmental\%20and\%20Green\%20chemistry/S4 \%20ORAL/OP20_Abstract_Katsaros.pdf (accessed on 11 August 2015).

5. Scott, G. Photo-biodegradable plastics: Their role in the protection of the environment. Polym. Degrad. Stable 1990, 29, 135-154. [CrossRef]

6. Roy, P.K.; Surekha, P.; Raman, R.; Rajagopal, C. Investigating the role of metal oxidation state on the degradation behaviour of LDPE. Polym. Degrad. Stable 2009, 94, 1033-1039. [CrossRef]

7. Männle, F.; Jørgensen, J.K.; Tanem, B.S. Increased performance of thermoplastic packaging materials by using a mild oxidizing biobased additive. Int. J. Polym. Sci. 2012, 2012, 297923. [CrossRef] 
8. Sipinen, A.J.; Rutherford, D.R. A study of the oxidative degradation of polyolefins. J. Environ. Polym. Degr. 1993, 3, 193-202. [CrossRef]

9. Bartlett, P.D.; Nozaki, K. The kinetics of decomposition of benzoyl peroxide in solvents. J. Am. Chem. Soc. 1946, 68, 1686-1692.

10. Tobolsky, A.V.; Mesrobian, R.B. Organic Peroxides-Their Chemistry, Decomposition and Role in Polymerization; Interscience Publishers, Inc.: New York, NY, USA, 1954; p. 55.

11. Salem, I.A. Role of aliphatic diamine ligands in hydrogen peroxide decomposition with Dowex-50W resin as transition metal complex ions. J. Mol. Catal. 1993, 80, 11-19. [CrossRef]

12. Eyler, G.N.; Canizo, A.I.; Alvarez, E.E. Thermal decomposition of cyclic organic peroxides in aliphatic amines solution. Afinidad Barcelona 2007, 64, 538-542.

13. Tidjani, A. Comparison of formation of oxidation products during photo-oxidation of linear low density polyethylene under different natural and accelerated weathering conditions. Polym. Degrad. Stabil. 2000, 68, 465-469. [CrossRef]

14. Chiellini, E.; Corti, A.; Swift, G. Biodegradation of thermally-oxidized, fragmented low-density polyethylenes. Polym. Degrad. Stabil. 2003, 81, 341-351. [CrossRef]

15. Koutny, M.; Sancelme, M.; Dabin, C.; Pichon, N.; Delort, A.-M.; Lemaire, J. Acquired biodegradability of polyethylene containing pro-oxidant additives. Polym. Degrad. Stabil. 2006, 9, 1495-1503. [CrossRef]

16. Chiellini, E.; Corti, A.; D’Antone, S.; Baciu, R. Oxo-biodegradable carbon backbone polymers-Oxidative degradation of polyethylene under accelerated test conditions. Polym. Degrad. Stabil. 2006, 91, 2739-2747. [CrossRef]

17. Kumanayaka, T.O.; Parthasarathy, R.; Jollands, M. Accelerating effect of montmorillonite on oxidative degradation of polyethylene nanocomposites. Polym. Degrad. Stabil. 2010, 95, 672-676. [CrossRef]

18. Corti, A.; Muniyasamy, S.; Vitali, M.; Imam, S.H.; Chiellini, E. Oxidation and biodegradation of polyethylene films containing pro-oxidant additives: Synergistic effects of sunlight exposure, thermal ageing and fungal biodegradation. Polym. Degrad. Stabil. 2010, 95, 1106-1114. [CrossRef]

19. Yashchuk, O.; Portillo, F.S.; Hermida, E.B. Degradation of polyethylene film samples containing oxo-degradable additives. Procedia Mater. Sci. 2012, 1, 439-445. [CrossRef]

20. Briggs, D.; Brewis, D.M.; Konieczko, M.B. X-ray photoelectron spectroscopy studies of polymer surfaces. J. Mater. Sci. 1979, 14, 1344-1348. [CrossRef]

21. Junnila, J.; Savolainen, A.; Forsberg, D. Adhesion Improvements between Paper and Polyethylene by Pre-Treatment of Substrate. In Polymers, Laminations and Coatings Conference, Orlando, FL, USA, 5-8 September 1989; pp. 353-360.

22. Savolainen, A.; Kuusipalo, J. The Optimization of Corona and Flame Pre-Treatment in Multilayer Coating. In Proceedings from the 1991 Tappi Extrusion Coating Short Course, Düsseldorf, Germany; 1991; pp. 897-904.

23. Li, G.Z.; Wang, L.C.; Ni, H.; Pittman, C.U. Polyhedral oligomeric silsesquioxane (POSS) polymers and copolymers: A review. J. Inorg. Organomet. Polym. 2001, 11, 123-154. [CrossRef] 
24. Markovic, E.; Constantopolous, K.; Matisons, J.G. Polyhedral Oligomeric Silsesquioxanes: From Early and Strategic Development through to Materials Application. In Application of Polyhedral Ologomeric Silsequioxanes; Hartmann-Thompson, C., Ed.; Advances in Silicon Science. Springer Netherlands: Dordrecht, The Netherlands, 2011; Volume 3, pp. 1-46.

25. Fina, A.; Tabuani, D.; Frache, A.; Camino, G. Polypropylene-polyhedral oligomeric silsesquioxanes (POSS) nanocomposites. Polymer 2005, 46, 7855-7866. [CrossRef]

26. Fina, A.; Tabuani, D.; Frache, A.; Camino, G. Polypropylene-polysilsesquioxane blends. Eur. Polym. J. 2010, 46, 14-23. [CrossRef]

27. Joshi, M.; Butola, B.S.; Simon, G.; Kukaleva, N. Rheological and viscoelastic behavior of HDPE/octamethyl-POSS nanocomposites. Macromolecules 2006, 39, 1839-1849. [CrossRef]

28. Joshi, M.; Butola, B.S. Isothermal crystallization of HDPE/octamethyl polyhedral oligomeric silsesquioxane nanocomposites: role of POSS as a nanofiller. J. Appl. Polym. Sci. 2007, 105, 978-985. [CrossRef]

29. Zhou, Z.; Zhang, Y.; Zhang, Y.; Yin, N. Rheological behavior of polypropylene/octavinyl polyhedral oligomeric silsesquioxane composites. J. Polym. Sci. Polym. Phys. 2008, 46, 526-533. [CrossRef]

30. Misra, R.; Fu, B.X.; Morgan, S.E. Surface energetics, dispersion and nanotribomechanical behavior of POSS/PP hybrid nanocomposites. J. Polym. Sci. Polym. Phys. 2007, 45, 2441-2455. [CrossRef]

31. Sánchez-Soto, M.; Schiraldi, D.A.; Illescas, S. Study of the morphology and properties of melt-mixed polycarbonate-POSS nanocomposites. Eur. Polym. J. 2009, 45, 341-352. [CrossRef]

32. Bourbigot, S.; Turf, T.; Bellayer, S.; Duquesne, S. Polyhedral oligomeric silsesquioxane as flame retardant for thermoplastic polyurethane. Polym. Degrad. Stabil. 2009, 94, 1230-1237. [CrossRef]

33. Lim, S.K.; Hong, E.P.; Choi, H.; Chin, I.J. Polyhedral oligomeric silsesquioxane and polyethylene nanocomposites and their physical characteristics. J. Ind. Eng. Chem. 2010, 16, 189-192. [CrossRef]

34. Nguyen, T.-A.; Männle, F.; Gregersen, Ø.W. Polyethylene/octa-(ethyl octadeca-10,13-dienoamide) silsesquioxane blends and the adhesion strength to paperboard. Int. J. Adhes. Adhes. 2012, 38, 117-124. [CrossRef]

35. Männle, F.; Tofteberg, T.R.; Skaugen, M.; Bu, H.; Peters, T.; Dietzel, P.D.C.; Pilz, M. Polymer nanocomposite coatings based on polyhedral oligosilsesquioxanes: Route for industrial manufacturing and barrier propreties. J. Nanopart. Res. 2011, 13, 4691-4701. [CrossRef]

36. Rao, C.N.R. Chemical Applications of Infrared Spectroscopy; Academic Press: Waltham, MA, USA, 1963; pp. 125-263.

37. Abrahamson, H.B.; Lukaski, H.C. Synthesis and characterization of iron stearate compounds. J. Inorg. Biochem. 1994, 54, 115-130. [CrossRef]

38. Zweifel, H. Plastic Additives Handbook, 5th ed.; Hanser Gardner Publications: Munich, Germany, 2001; pp. 8-9. 
39. Eyenga, I.I.; Focke, W.W.; Prinsloo, L.C.; Tolmay, A.T. Photodegradation: A solution for the shopping bag "visual pollution" problem? Macromol. Symp. 2002, 178, 139-152. [CrossRef]

(C) 2015 by the authors; licensee MDPI, Basel, Switzerland. This article is an open access article distributed under the terms and conditions of the Creative Commons Attribution license (http://creativecommons.org/licenses/by/4.0/). 